\title{
OBJECTILE E AS “NOVAS PRETENSÕES” DO PROJETO PARAMÉTRICO EM ARQUITETURA
}

\section{OBJECTILE AND THE "NEW PRETENSIONS" OF PARAMETRIC DESIGN IN ARCHITECTURE}

\section{Rovenir Bertola Duarte', Malu Magalhães Sanches ${ }^{2}$, Louisa Savignon Lepri ${ }^{3}$}

RESUMO: Na década de 1980, Deleuze e Cache produzem um novo conceito encapsulado em uma "palavra bárbara", o objectile, um tipo de objeto variável, no qual, segundo Deleuze, a flutuação da norma substitui a permanência de uma lei, a produção de um contínùo por variação. Às vezes, uma palavra bárbara é necessária para dar conta de uma "pretensão nova", um vetor de saída de territórios conhecidos. Quais "pretensões novas" poderiam revelar esse conceito sobre o processo de projeto arquitetônico na era digital? Nesta investigação, propomos pensar o que aconteceria se tomássemos o objectile como objeto do processo de projeto arquitetônico para revelar tais pretensões; se trocássemos um objeto fixo por outro variável, um molde por outro modulado. Apresentamos três níveis de reflexão sobre o projeto paramétrico digital na arquitetura: (a) o objectile e sua relação no processo como ferramenta da variabilidade: caminho para o meta-design; (b) o objectile na questão da escolha dentro do processo projetual: um controle modulado; e (c) o objectile no impacto sobre novas formas de pensar o projeto por dentro: amnésia e inconsciência algorítmica. Por fim, buscamos entender a perturbadora mudança conceitual trazida por essa ideia de projeto baseada em um "contínuo por variação", afetando formas de pensar e conceitos como processo, controle, liberdade e escolha.

\section{PALAVRAS-CHAVE: Objectile; Projeto Paramétrico; Gilles Deleuze; Modulado; Projeto Digital.}

ABSTRACT: In the 1980s, Deleuze and Cache produced a new concept encapsulated in a "barbaric word", the objectile, a variable object type, where, according to Deleuze, fluctuation of the norm replaces the permanence of a law in the production of the continuum by variation. Sometimes a barbaric word is necessary to deal with a "new pretension", an exit vector from known territories. Which "new pretensions" could reveal this concept about the architectural design process in the digital age? In this investigation we propose to think what would happen if we took the objectile as the object of the architectural design process to reveal such new pretensions; if we exchanged a fixed object for a variable one, or a mold object for a modulated one. We present three levels of reflection on the digital parametric design in architecture from this point of view: (a) objectile and its relationship in the process as a tool of variability; a path to meta-design; (b) objectile in the matter of choice within the design process: a modulated control; and (c) objectile in the impact on new ways of thinking within the design process: amnesia and algorithmic unconscious. Lastly, we seek to understand the disturbing conceptual change brought by this design idea based on a "continuum by variation", affecting the concepts as design process, control, freedom, choice and ways of thinking.

KEYWORDS: Objectile; Parametric Design; Gilles Deleuze; Modulated; Digital Design.

\section{How to cite this article:}

DUARTE, R. B.; SANCHES, M. M.; LEPRI, L. S. Objectile e as "novas pretensões" do projeto paramétrico em arquitetura. Gestão e Tecnologia de Projetos, São Carlos, v. 12, n. 3, p. 59-76 2017. http://dx.doi.org/10.11606/gtp. v12i3.134297 


\section{INTRODUÇÃO}

Na década de 1980, o arquiteto e teórico francês Bernard Cache questiona “o que é um objeto nos dias de hoje?”. A pergunta ecoa uma tal "crise do objeto" que tem assolado, vez ou outra, a arquitetura desde o último quarto do século XX (HARTOONIAN, 2006; MONTANER, 2008; ROWE; KOETTER, 1980). Junto com esta pergunta, Cache (1995) nos brinda com um novo conceito de objeto, como explica o filósofo Gilles Deleuze (1991, p. 38), “uma concepção muito contemporânea de objeto tecnológico” . Esse conceito vem encapsulado num estranho neologismo, objectile, a junção das palavras francesas object + projectile. Um tipo de "palavra bárbara", mas, como novamente nos fala Deleuze, "precisamos, às vezes, inventar uma palavra bárbara para dar conta de uma noção com pretensão nova" (DELEUZE; PARNET, 1996, p. 5, grifo nosso), algo que funcione como um vetor de saída de territórios já muito desbravados. Aproveitamos essa "palavra bárbara" para entender sua relação com o projeto arquitetônico na era digital, especificamente o paramétrico, e as "novas pretensões".

Este trabalho parte das reflexões de Cache e Deleuze, na busca por "novas pretensões". A proposta metodológica foi pensar o que aconteceria se tomássemos o objectile como objeto do processo de projeto arquitetônico. Entender o potencial perturbador desse conceito e da substituição de algo como o blueprint, uma "representação-molde" que comumente o edifício precisa respeitar para existir, por um objeto variável. Acreditamos poder auxiliar uma investigação teórica especulativa sobre o projeto paramétrico e seus caminhos futuros, já que a parametria parece ser conhecimento essencial para essa substituição. Assim, vamos ao encontro da mudança paradigmática que alguns autores (CARPO, 2011a; CHOKHACHIAN, 2014; GANE, 2004) acreditam que o projeto digital paramétrico ajudará a produzir. Nessa troca do objeto fixo por outro variável, buscamos refletir a ideação de objeto do projeto paramétrico digital na arquitetura em três níveis: (a) o objectile e sua relação no processo como ferramenta da variabilidade: caminho para o metadesign; (b) o objectile na questão da escolha dentro do processo projetual: um controle modulado; e (c) o objectile no impacto sobre novas formas de pensar o processo de projeto, tratando da amnésia e da inconsciência algorítmica.

Para iniciarmos essa busca por "novas pretensões", antes, deveremos trilhar um caminho para entender o significado filosófico do termo, como também sua relação com o projeto digital paramétrico e com a vida contemporânea, atravessada por desejos de consumo. Devido a essa crise do objeto, ou de sua concepção muito contemporânea, deveríamos nos perguntar sobre as “novas pretensões” do objeto do projeto no futuro, uma reflexão sobre controle, liberdade, escolha e formas de pensar. Acreditamos que o conceito de objectile possa nos ajudar nessa tarefa.

\section{ENTENDENDO O OBJECTILE: FILOSOFICAMENTE, DIGITALMENTE E SOCIALMENTE}

Do encontro entre professor e aluno, no Centre Universitaire Vincennes, entre arquiteto e filósofo, Cache e Deleuze constroem a ideia de objectile nos anos 1980. Unidos pelo interesse por Leibniz, ambos tateiam uma nova concepção de objeto variável. Em 1983, sob o título Terre meuble, Cache escreve sobre esse conceito, mas, possivelmente, sem as citações de Deleuze em Le Pli: Leibniz et le Baroque, publicado em 1988; este passaria despercebido. Por outro lado, segundo Cache e Girad (2013), foi o próprio filósofo quem concebeu a palavra; de sua fértil mente geradora de termos desconcertantes brota esse neologismo com a força necessária de uma "palavra bárbara”. Após a morte de Deleuze em 1995, Cache e Patrick Beaucé apresentam uma exposição chamada "Objectile", com objetos de design non-standards, calculados em computadores e produzidos em máquinas 
CNC. Um conceito que nasce da potente relação entre filosofia e tecnologia, entre Leibniz e processos digitais. Uma produção de um objeto único com múltiplas capas temporais. Um objeto variável para uma sociedade desejosa por constante mudança. Desse modo, o conceito já nasce associado ao digital design, à parametria, a um entendimento de objeto na contemporaneidade, como também à filosofia. No próximo item, um entendimento filosófico, tecnológico e social do conceito.

\section{O objectile e sua relação filosófica}

Gottfried Leibniz era o ponto de conexão entre Cache e Deleuze na época da criação do conceito de objectile. Não é difícil imaginarmos a relação entre o pensador do século XVII e a nova ideia de objeto variável. Cabe antes lembrarmos que naquele período o pensamento corrente sobre substância baseava-se nas ideias de res cogitans ("algo que pensa") e res extensa ("coisa extensa"), de René Descartes. Mais especificamente, a res extensa se tornaria um modo quase de senso comum de conferir substancialidade aos corpos, a ideia geométrica pela qual o corpo é apenas uma substância extensa em comprimento, largura e altura. Esse modo de entender os corpos materiais tornou-se trivial; pensamos os objetos, como uma garrafa ou um edifício, pelas extensões de comprimentos, larguras e alturas. No entanto, poucas décadas depois da publicação do pensamento do francês, Leibniz firmou um contraponto. Como observa Lacerda (2016), o pensador alemão parece dialogar com a filosofia de Descartes a fim de criticá-la. Para Leibniz, o pensamento mecanicista cartesiano e a concepção quantitativa de res extensa pareciam insuficientes para conferir unidade e substancialidade aos corpos. O pensamento de Leibniz trata os corpos através de noções de força e ação, consideradas por ele mais fundamentais que as estáticas extensões.

Como aclara Lacerda (2016, p. 159), o corpo para Leibniz deixaria de ser explicado em termos de massa extensa, pois não bastaria para tratar da “multiplicidade das substâncias”. Na visão dele, os corpos são formados por inúmeros outros corpos, multiplicadosaoinfinito, como explica Montefameglio (2016), a partir de uma matéria caótica com natureza confusa. Assim, a res extensa se mostra insuficiente porque o objeto não estaria mais definido por uma forma essencial e não seria bem determinado. O corpo é compreendido como material, mas isso não significa dizer que seja efetivamente extenso, e sim percebido como extenso (LACERDA, 2016). Segundo Montefameglio (2016), não é que não existissem objetos para Leibniz, mas eles ganham outro estatuto: o de um ato em movimento, ato de mudança, como explica Deleuze (1991, p. 33), um puro evento. A substância seria ativa e sua unidade estaria na capacidade de atuar; individual e múltipla, portanto: individual por ser unidade, mas múltipla por tratar de variação.

Deleuze e Cache também se interessaram pelos textos matemáticos de Leibniz, uma espécie de "matemática barroca" que "toma a variação como objeto" (DELEUZE, 1991, p. 37). O filósofo francês comenta a ideia leibniziana de uma família de curvas dependentes de parâmetros, por meio dos quais aconteceria a redução das variáveis a uma só e única variabilidade. Desse modo, o "objeto já não se define por uma forma essencial” (DELEUZE, 1991, p. 38), mas sim através de uma família de variações. Um objectile trataria de muitos objetos em potência, incorporando a variabilidade. Nilsson (2007) explica que, em termos aristotélicos, trata-se de muitos objetos, mas em termos deleuzeanos, um objectile seria uma forma em muitos eventos possíveis. Diferente da visão cartesiana de extensão, que por meio de leis regulares da geometria clássica conseguiu definir um corpo fixo, esse objeto variável necessitaria de leis mais dinâmicas, nas quais "a flutuação da norma substitui a permanência de uma lei, quando o objeto ocupa lugar em um contínuo por variação" (DELEUZE, 1991, p. 38). 


\section{O objectile e seu vínculo com o projeto digital paramétrico}

Não é por acaso que Deleuze descobria similaridade entre o trabalho paramétrico de Cache e a proposta barroca de Leibniz. Ambos encontravam nas leis matemáticas um modo de produzir variabilidade. Quando Deleuze (1991, p. 38) falou ao grande público sobre o objectile, também o descreveu como uma espécie de família "enquadrada por parâmetros". Para incorporar a variabilidade como objeto, seria necessário mais que uma geometria estática, demandaria um tipo de matemática que alcançasse algo que Deleuze chamou de "pura funcionalidade". Aqui o termo função, na raiz de funcionalidade, se refere ao conceito matemático segundo o qual algo está em função de outro elemento, trazendo para o centro da questão correspondências e associações, delimitando uma família e suas variações.

Anos depois, Carpo (2011b) ressaltou a questão dos parâmetros na definição do objectile: uma infinita variedade de objetos, todos distintos em alguns parâmetros e semelhantes em outros.

Para entendermos essa relação entre objectile e parametria como funções, tomaremos uma equação hipotética: ax $2+$ by $+c z+d=0$, onde costumeiramente temos uma série de parâmetros evariáveis correspondendo a (ou em função de) zero. Nesse caso, os parâmetros seriam os termos da equação, ou seja, a, b, c e d, enquanto as variáveis seriam os componentes x, y e z. Como Kolarevic (2005) descreve a projeto paramétrico: equações gerando diferentes objetos. Os parâmetros são os elementos que definem um sistema e determinam ou limitam seu desempenho, enquanto as variáveis tratam do alcance de maleabilidade dessa função. Pensando na equação como um conjunto de curvas, pois a cada alteração de variável seria possível obter uma nova curva, vemos a clara semelhança com a família de objetos que o objectile ou o projeto paramétrico tratam (Figura 1). Nesses casos os parâmetros tratariam das magnitudes (GARCÍA ALVARADO; JOFRE MUÑOZ, 2012) pela função, forma paramétrica ou objectile, devendo de algum modo ser aspectos mensuráveis, quantitativos ou qualitativos (GANE, 2004). Assim cada termo (a, b, c...) poderá estar associado a aspectos quantitativos, como dimensões extensivas, temperaturas, pressões, velocidades..., ou a algum tipo de padrão, com traços mais qualitativos, como o estado de emoção de um indivíduo (felicidade, amor, medo ou ódio, como no caso do D-Tower e suas quatro cores).

Figura 1: Equação como um conjunto de variações da mesma forma

Fonte: Elaborada pelos autores
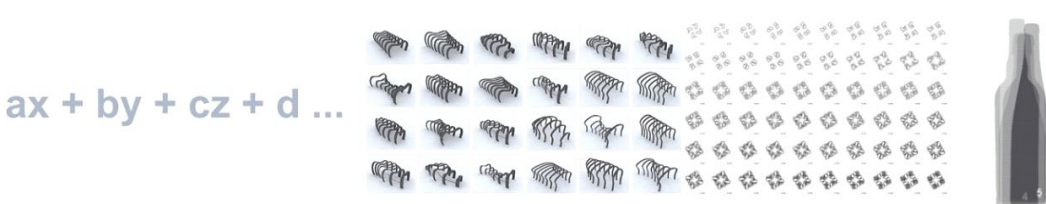

Com uma ambição didática, falaremos de mais dois aspectos implícitos dessa função: associação e modulação. No caso da associação, trata-se do próprio desenho da função, ou seja, de como ela relaciona, organiza e hierarquiza seus próprios componentes. Aqui aparece o desenho algorítmico da função através de códigos, bifurcações, ligações... que ao mesmo tempo desenham a família de objetos. Por outro lado, o segundo aspecto implícito trata da modulação, pois cada $\mathrm{x}$, y ou $\mathrm{z}$ varia provavelmente dentro de um intervalo, produzindo uma modulação de variação nessa família. Em resumo, os parâmetros correspondem ao conjunto de termos escolhidos e considerados para a construção da família, podendo ser fixos ou não, por exemplo, \{pé-direito, altura-peitoril, largura-janela, altura-janela, áreas, inclinação solar...\} para um objectile de uma janela em função da entrada de sol, ou \{raio superior, raio inferior, raio intermédio, alturas, volumes...\} para o objectile de uma garrafa em função de seu volume. Contudo, como nem todos os termos são fixos, existe a necessidade de determinar quais são os variáveis e as modulações dessas variações. Surgem, então, os x 
ou y que podem dizer quanto o sol em altura irá variar, dentro de uma modulação específica, como de $90^{\circ}$ a $42^{\circ}$ em função de uma latitude conhecida. Ao final, essa inclinação precisará se associar a outros termos para adquirir uma lógica algorítmica, podendo surgir o peitoril, a alturajanela ou o pé-direito, desenhados como fixos ou não. Nesse sentido, o objectile e o projeto paramétrico tratam dos mesmos elementos: parâmetros, variáveis, modulações e associações; pela variabilidade e através da "purafuncionalidade”.

Também é importante destacar, como nos lembram García Alvarado e Jofre Muñoz (2012), que o projeto paramétrico vai além do simples emprego de parâmetros, afinal toda operação de desenho digital os usa. Os autores explicam que o projeto paramétrico compreende um tipo de raciocínio codificado ligado a um documento e a um processo de modelagem, podendo ao final dar suporte à fabricação de um sem número de componentes diferentes. Para Nilsson (2007), o uso de parâmetros no processo de projeto torna possível contextualizar o objeto arquitetônico e torná-lo ajustável às situações em que ele deve funcionar. Por essa razão, Gane (2004) destaca que o projeto paramétrico é marcado pelo processo de escolha de parâmetros e por restrições relacionadas com um problema, todos associados de algum modo (por exemplo, a inclinação de um brise vertical associa-se à orientação de um edifício). Parâmetros, variáveis, modulações e associações estarão em um modelo que poderá ser usado para explorar diferentes alternativas de solução de projeto e em diferentes trabalhos (Figura 2). O projeto assim funciona como um objectile, já que carrega em um só modelo diversos objetos ou, em linguagem de Leibniz, um objeto que se desdobra em muitos: variável. Vejamos como esse tipo de objeto se aproxima da nossa sociedade de consumo. parâmetros

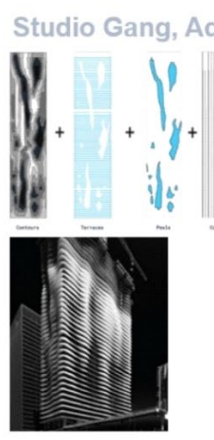

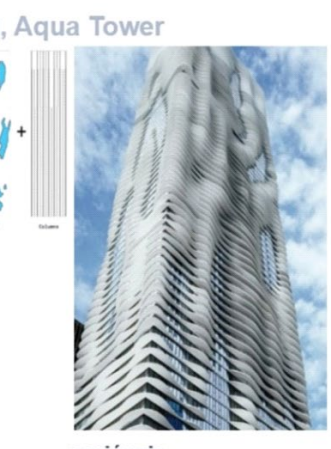

variáveis

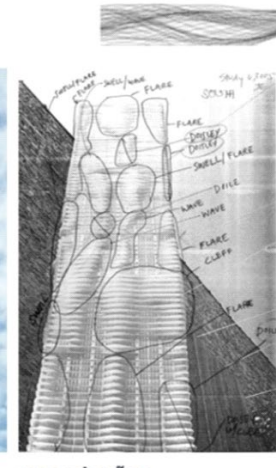

associações

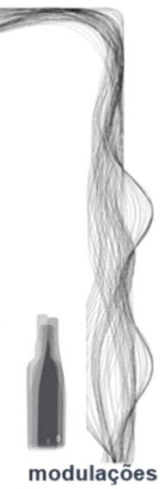

\section{O objectile e sua relação com o mundo de consumo: a odisseia da vida de um produto}

Antes de iniciarmos a reflexão sobre as novas pretensões que o objectile poderá estimular em relação ao projeto paramétrico, cabe pensarmos um pouco sobre o porquê do emprego desse tipo de objeto variável na contemporaneidade. Realmente podemos dizer que a sociedade de consumo tem produzido um forte impacto na imagem do objeto. Como descreve Baudrillard (2004), vivemos em um mundo marcado por uma imensa fauna de objetos se sucedendo em ritmo acelerado, onde o ser humano se assenta diante de gerações de produtos e gadgets, vendo-os se tornarem, um a um, obsoletos. Kwinter (2003) corrobora a ideia afirmando que o objeto idealizado na modernidade industrial, produzido "por e para as massas" (DELEUZE, 1991), parece desgastar-se rapidamente nesse contexto. Tal objeto, baseado na constância da lei para fabricação em série, agora conflita com a velocidade e variabilidade da época contemporânea. Para Cache (1995, p. 95), um objeto diferente emergiria apoiado em "um novo contrato
Figura 2: Parâmetros, variáveis, associações e modulações em um projeto arquitetônico

Fonte: Adaptada de Nyawara (2015) 
de utilização ou produção", pois adentramos uma época em que o "objeto idêntico seria um tipo de contrato não mais viável” (KWINTER, 2003, p. 99). Para entender melhor esse novo contrato, seguiremos o caminho proposto por Cache (1995), uma espécie de odisseia sobre a vida de um produto tecnológico na atualidade, dividida em seis fases: consumo, produção, representação, modelagem, função e marketing.

O consumo partiria de uma imagem do objeto que não se relaciona mais com a funcionalidade expressa por este, mas com inflexões expostas por nosso comportamento flutuante. Assim, a constância de uma lei ou tradição não é adequada para representar o consumo, pois ele é baseado na própria mudança.

Dessa maneira, a produção de objetos, possibilitada pelo desenvolvimento tecnológico, tornou-se igualmente dinâmica. O molde, entendido como estático, fica substituído pela modulação variável (Figura 3). Ao contrário da divisão da produção industrial em série, na qual o objeto se subordina a uma geometria preexistente, a produção atual é resultado da combinação de parâmetros variáveis possíveis de serem materializados.

Então, a próxima fase, a representação do objeto, tem seu status alterado pela era das imagens publicitárias, espalhadas ferozmente nos meios digitais. A própria imagem vendida do produto vira peça de consumo, precedendo o objeto-mercadoria. Assim, sua volatilidade torna obsoletas formas de representação tradicionais e rígidas, como os protótipos. O objeto, agora modulado e não mais moldado, vira efeito possível das intersecções de parâmetros estabelecidos. Antes restrito ao molde, o objeto não imita mais algo representado; no tempo atual passa a ser simulado e atualizado por softwares, modelagem CAD/CAM e fabricação por sistemas CNC.

A função de tais objetos modulados, por outro lado, torna-se independente, uma vez que o processamento dos dados, fruto das intersecções de parâmetros, é realizado por placas de circuitos integrados. A forma física/material ou qualquer outra propriedade mecânica não possui mais relação com a função eletrônica programada para o objeto. Por trás disso estaria um tipo de linguagem digital que possibilita a interação entre diferentes aparelhos tecnológicos, visto que é constituída essencialmente por eleições binárias ( 0 ou 1 ) presentes em todos os tipos de gadgets digitais.

Por último, o marketing oferece a própria imagem da norma flutuante. Uma imagem variável, entre o produto padronizado e uma personalização do produto para cada cliente, algo que flutua sobre uma curva de variação mapeada com a pretensão de atingir relações singulares com o usuário.

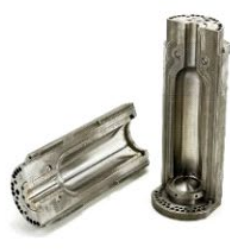

Molde

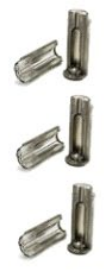

.
Itilitill dubum 808888880 doubua
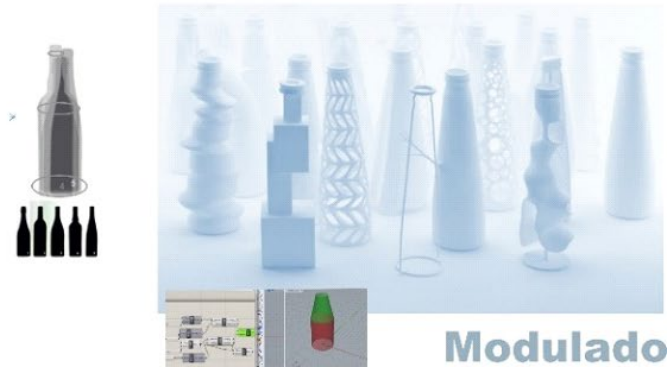

Figura 3: Moldar é modular de maneira definitiva, modular é moldar de maneira contínua e variável

Fonte: Adaptada de Andrea Morgante (ITALIAN..., 2014)
A vida do produto nasce da convivência entre uma sociedade que clama intensamente por personalização e sua limitação no atendimento dessa individualização. Assim, necessita flutuar sobre uma curva de variação. Não busca a massa nem o indivíduo, mas através de customizações, o produto tenta alcançar um conjunto nebuloso. Dessa demanda por variabilidade, o marketing surge para produzir imagens que parecem se referir ao produto, mas na verdade mostram que o produto é sim, em primeiro lugar, a própria imagem. Vivemos no mundo das logomarcas. Por outro lado, marketing e função se entrelaçam, pois o primeiro fabrica no 
usuário o desejo e a sensação da segunda. A função também se aproxima cada vez mais da variação, até mesmo porque, com a manipulação numérica de dados digitais, um objeto pode ter o mesmo código de outro. Uma fachada de edifício pode desejar ser imagem ou música - como na Hyposurface do dECOi, um tipo tão radical de nova mídia controlada por números que pode ligar uma parede a imagens e sons.

Esse conceito de produto, nascido sob a ameaça de um prejuízo, imprime sua variabilidade também na modelagem, que não mais repete um modelo fixo, mas acontece a partir da interseção de parâmetros. Por outro lado, sua representação precisa revelar a mesma variabilidade e maleabilidade, mostrando o objeto sendo calculado em tempo real, em vez de projeções congeladas. Uma geografia das possibilidades plasmada em uma imagem CAD/CAM (CACHE, 1995).

A produção abandona os moldes fixos e as formas predefinidas e reflete tal variação em uma modulação interpretada por máquinas CNC. Essa modulação garante uma gama de pequenas mudanças e customizações que, de alguma forma, correspondem à própria curva de oferta e procura introjetada no produto. A mudança de contrato vigente na associação contemporânea entre homem e objeto não mais se basearia na estandardização e na lei da constância. Um frutífero mundo para o objectile.

\section{TRÊS NÍVEIS DE REFLEXÃO: O OBJECTILE COMO UMA NOVA PRETENSÃO PARA O PROJETO ARQUITETÔNICO}

Qual transformação poderia ocasionar tal mudança no conceito de objeto, saindo de um fixo para outro variável? Para nos debruçarmos sobre essa questão, propomos refletir a respeito das mudanças do processo projetual em três níveis. O primeiro destaca as ferramentas e a variabilidade envolvidas, pensando que toda alteração de ferramenta implica potencial transformação de processo; neste caso, trazemos a ideia de meta-design. $O$ segundo nível volta-se para as mudanças de mecanismo de escolha dentro do processo, pois a troca do objeto fixo por um variável implica alguma alteração relacionada com opções e escolhas (liberdade e controle). Por fim, o terceiro nível se dedica ao pensamento dentro do processo, buscando rastrear possíveis alterações em sua natureza.

\section{Ferramenta da variabilidade em busca de um novo processo: o meta-design}

Quando pensamos no processo de projeto, não é difícil imaginarmos um projetista debruçado sobre um croqui, onde, através de movimentos frenéticos, busca, em um mar de opções e riscos, a eliminação das diversas opções na procura da ideia certa. Pouco a pouco, da sobreposição de traçados leves, surge ao final a linha definitiva e forte, de onde a "forma essencial" emerge. Essa descrição, ainda que romantizada, revela seguramente algo sobre como pensamos o processo de projeto: do múltiplo para o único, um percurso de redução de variáveis. No entanto, como destaca Deleuze (1991, p. 38), o objectile também sugeriria a redução de variáveis, a redução "a uma só e única variabilidade". Nesse caso, poderíamos pensar o processo de modo diferente, cujo resultado chamado de "final" não se trataria de uma "forma essencial", mas sim de um objeto variável, e aqui tomaríamos o objectile como objeto do processo do projeto. Dessa maneira, os projetistas não se dedicariam somente a produzir um produto por meio de ferramentas, mas o próprio produto de seu trabalho se tornaria uma ferramenta para novos produtos, raciocínio muito semelhante ao que tem sido chamado atualmente de meta-design. 


\section{A classificação de três aproximações do objectile como ferramenta em arquitetura}

Antes de tentarmos relacionar as transformações do processo de projeto e ferramentas com a inserção do conceito do objectile, é necessário que observemos três modos diferentes de aproximação entre o objeto variável e a arquitetura. Em outras palavras, se a variabilidade será tomada como objeto da arquitetura, cabe pensarmos em qual momento ou até onde essa variabilidade pode chegar. Apresentamos três graus de aproximação segundo a permanência e materialidade do objectile dentro do projeto:

(a) Objectile como variável do projeto (ferramenta morta - projeto tradicional incrementado): nesse caso o objeto variável será aplicado em um momento do projeto com a finalidade de encontrar uma solução adequada, para então congelarmos as opções. Assim, a multiplicidade de suas variáveis se manterá viva até a escolha de uma solução específica; em seguida, matamos o objectile. Essa aproximação o incorpora no processo mais tradicional de projeto. Não por casualidade, os exemplos levantados por García Alvarado e Jofre Muñoz (2012) sobre a origem do projeto paramétrico, com Gehry e Grimshaw, tratam do emprego da variabilidade para o "controle da forma". Exemplos podem ser dados com Studio Gang, no Aqua Tower, ou com Amanda Levete, no Hills Palace (Figura 4).

Figura 4: Objectile como ferramenta morta

Fonte: Adaptada a partir da imagem do Aqua Tower por Studio Gang (NYAWARA, 2015) e do 10 Hills Place por Amanda Levete Architects (ETHERINGTON, 2009)

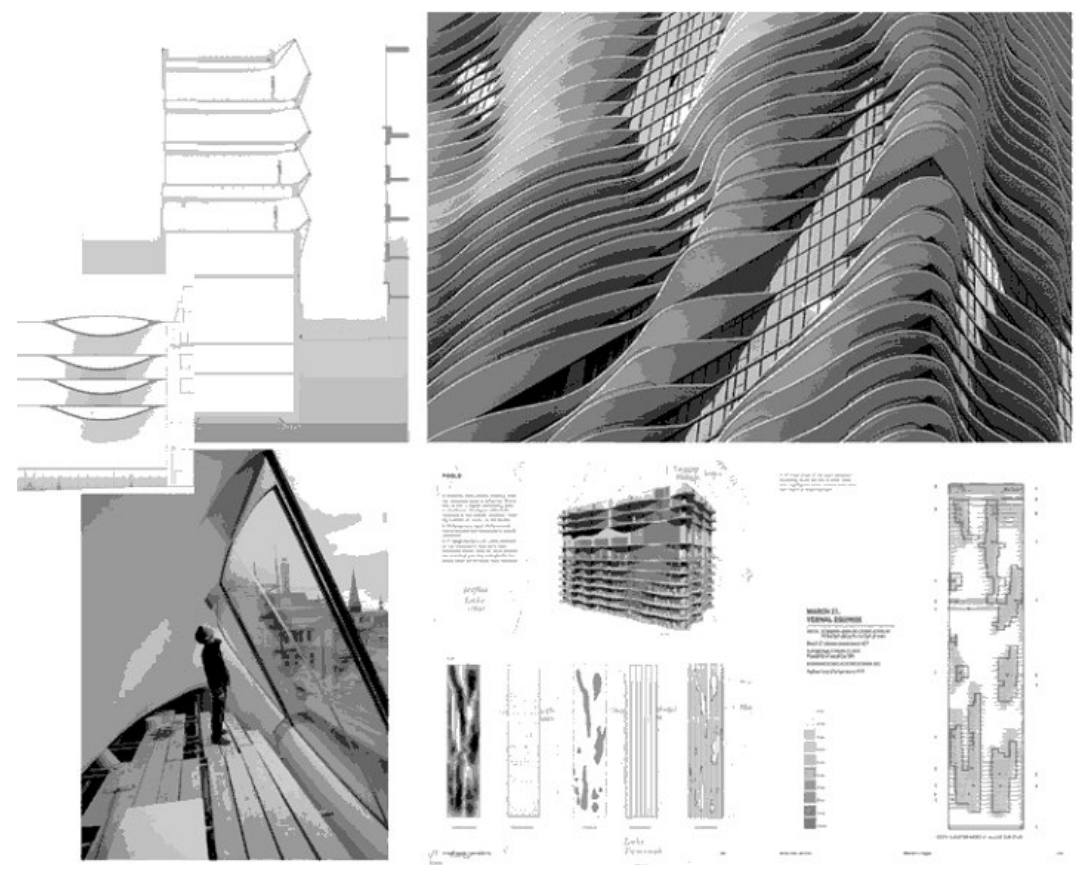

(b) Objectile como projeto variável (ferramenta viva - metadesign): nessa aproximação o projeto se concentrará na própria variabilidade do objeto. Em lugar de pensarmos uma solução adequada, trataríamos com uma gama de soluções e modulações. Nesse grau de aproximação o objectile se manteria vivo, inclusive para outros projetos, devido a sua capacidade de gerar um sem número de possibilidades. Nessa categoria o projetista pode, por exemplo, associar o objectile a variáveis para customização (caso da Variomatic house de ONL, bem como da arquitetura de Ming Tang), ou a tipos de conceito que serão reaplicados em projetos distintos (caso dos Design Models do UNStudio, conforme Duarte, 2015) (Figura 5). Pode ser pensado como um esqueleto paramétrico modulado (GANE, 2004) ou um primitivo variável (TRUMMER, 2011). 

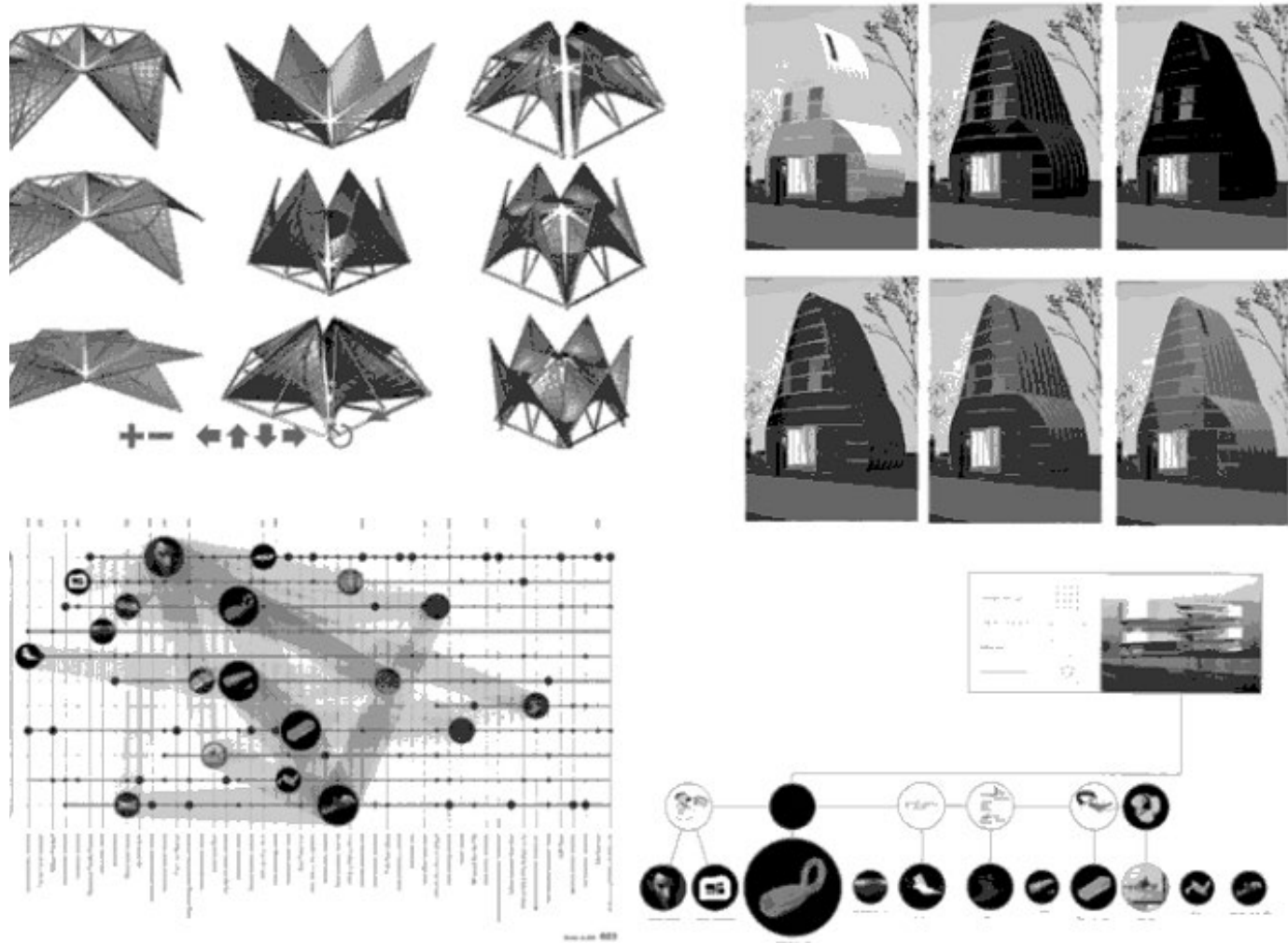

(c) Objectile como arquitetura (arquitetura variável): nesse último grau o objectile será materializado de alguma forma, sem perder suas variáveis. Para Nilsson (2007), trata-se de um novo tipo de tectônica, cuja oportunidade seria construir novas relações com o corpo, muito além do consumo visual do espaço. Aqui o objectile não se resume ao projeto. Contudo, essa aproximação envolve uma evolução tecnológica e um caminho novo a ser trilhado, assim, é marcada por atividades mais de vanguarda, como os trabalhos do protoSPACE coordenados por Kas Oosterhuis (Hyperbody TUDelft), Media-TIC building de Cloud 9, de Enric Ruiz Geli, e o já consagrado Pavillion Water do NOX (Figura 6).

Para pensarmos as relações entre a inserção desse conceito de objeto e as transformações do processo em meta-design, nos interessa mais a segunda aproximação (ferramenta viva), pois a primeira acaba se aproveitando parcialmente do potencial da variabilidade, matando-a em sua absorção pelo projeto tradicional, enquanto na terceira o foco vai além do próprio projeto, tateando uma nova arquitetura ou mesmo uma "nova tectônica" (NILSSON, 2007). Entretanto, no segundo caso, o projeto se concentra menos na concretização da forma visual e mais, como observa Carpo (2011b), em um pensamento baseado na transmissão de algoritmos invisíveis. Ainda que o italiano detecte um paralelo histórico com as ordens albertianas, ele destaca que a época atual lida com a passagem do mundo mecânico para o eletrônico, uma mudança da produção de objetos para a produção de simples sequências de números que, por sua vez, gerarão objetos (CARPO, 2011b). Assim, o projeto não se concentraria em produzir um objeto bem delimitado; em outras palavras, rejeita uma representação que congela as variáveis não eleitas para construir um molde em formato de desenhos blueprint. Carpo alerta que nenhum produto 'final' de qualquer processo digital é realmente final, mas apenas um produto ocasional de um processo algorítmico que poderá gerar muitos outros. Ou seja, o objectile surge como uma mudança de paradigma projetual.

Figura 5: Objectile como ferramenta viva, projeto variável Fonte: Adaptada de Duarte (2015) 

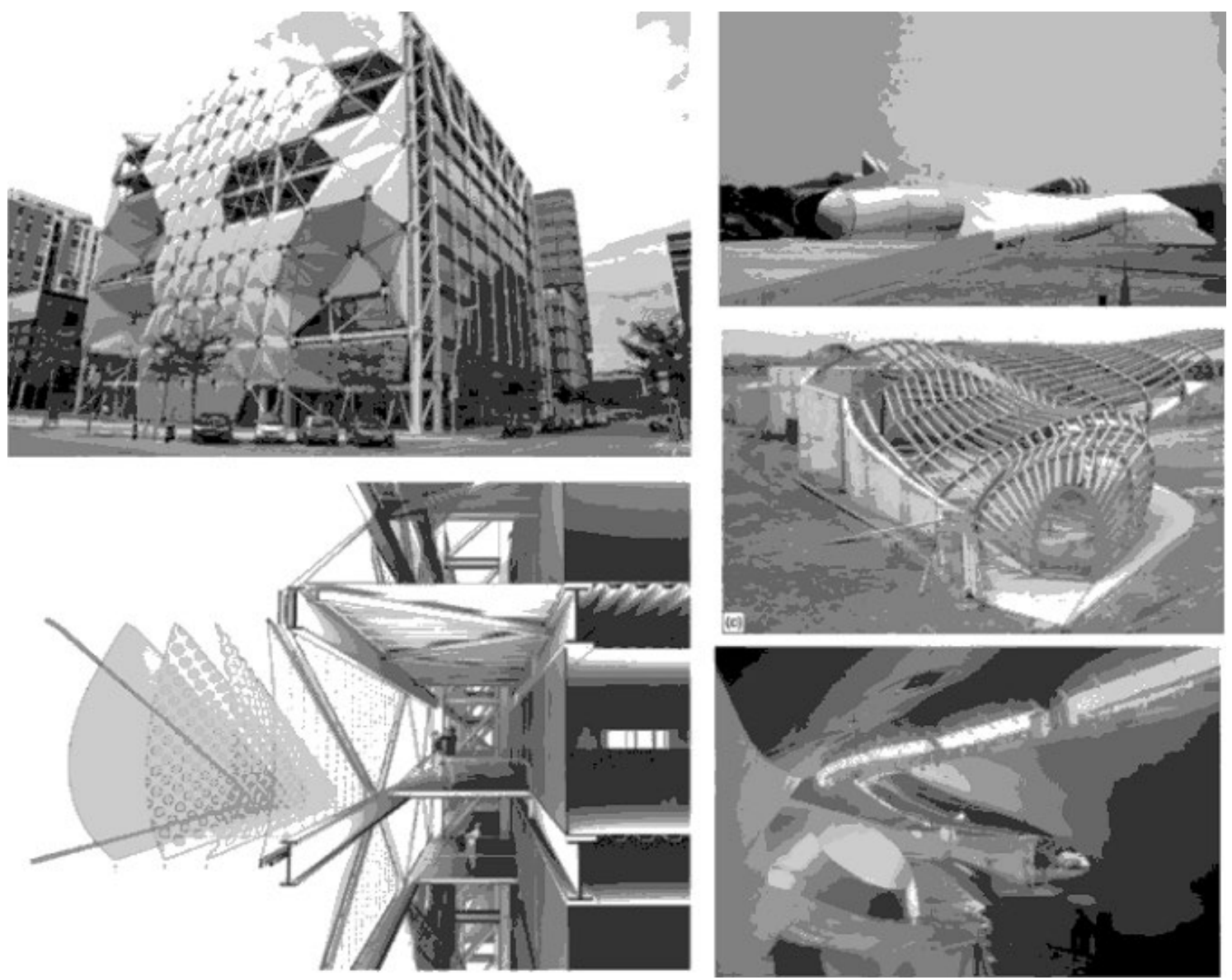

Figura 6: Objectile como arquitetura

Fonte: Adaptada de Geli (2010) e NOX ([201-?])

\section{O meta-design como uma nova ideia de projeto variável}

Nas últimas décadas, expressões bastante semelhantes, sugerindo a existência de meta-processos projetuais ou meta-projetos, têm sido empregadas em publicações acadêmicas (DUARTE, 2015; FISCHER, 2012; GIACCARDI, 2003; KOLAREVIC, 2005; MORAES, 2010; SANDERS; STAPPERS, 2008). O prefixo "meta" (do grego $\mu \varepsilon \tau a ́)$ aqui indicaria algo como "além" do projeto, na clara direção de uma "nova pretensão" para ele, pois, como observa Giaccardi (2003), o meta-design rejeita as abordagens de projeto estabelecidas. O "metadesign" desviaria do projeto do objeto em si (edifício ou garrafa), pois o objeto seria uma ferramenta ou um sistema dedicado a um meta-objeto (meta-edifício ou meta-garrafa), a partir do qual se poderia obter um objeto específico (um edifício ou uma garrafa). O que propomos é pensar nessa ferramenta ou nesse sistema, que trata do não finalizado, como um objectile, muitas formas em muitos eventos possíveis. Como explicam Kolarevic (2005) e Giaccardi, (2003), o projetista se dedicaria a projetar o projeto: “designing design”. Para Giaccardi (2003), nessa concepção o "meta” funcionaria como "atrás”, quando o projetista promove estruturas, sistemas ou ferramentas que permitam tal maleabilidade. 0 objeto não surgiria diretamente do processo, mas sim de um princípio generativo ou design para novos produtos.

Em continuação, Giaccardi (2003) também define "meta" como "junto" (designing together) e "entre" (designing the in-between), pensando que a concepção prosseguiria depois do processo do projetista, envolvendo usuários ("juntos") e em ambientes de interação ("entre"). Os usuários seriam vistos como agentes na solução de problemas (SANDERS; STAPPERS, 
2008). Buscando abarcar a complexidade da sociedade de consumo, alongase o processo de criação, inclusive, até o momento do uso. Trata-se de uma mudança de abordagem: antes se pensava um produto bem-acabado para ser consumido passivamente; agora todas as pessoas teriam meios de participar ativamente na elaboração de um produto (FISCHER, 2012). Surgiriam novos personagens, users as designers e metadesigners, misturando muitas vezes o tempo do projeto (design time) e o do uso (use time).

Nessa situação, o projetista necessitaria alterar sua visão de objeto, incorporando mais variabilidade, algo voltado para a colaboração e inclusão dos usuários, como também para a vida do produto na sociedade de consumo. Podemos imaginar um projeto dedicado a esse objeto variável, sem uma finalidade excessivamente específica, a "pura funcionalidade" deleuzeana, que possa transcender os conceitos de início e fim de projeto, em prol de um projeto continuado. Uma forma flutuante que trabalhasse dentro de uma faixa variável modulada, podendo atravessar diversos outros projetos e, de modo não linear, talvez conseguisse entrar e sair do processo a qualquer momento (Figura 7). Um tipo de projeto que se constrói temporalmente, em harmonia com a flutuação do comportamento contemporâneo e sua demanda por escolhas para satisfação. A promessa de um projeto contínuo, não linear, cocriativo e coevolutivo, sem dúvida, uma significativa "pretensão nova" para o processo projetual, diretamente relacionada com o escolher, tema da próxima reflexão.

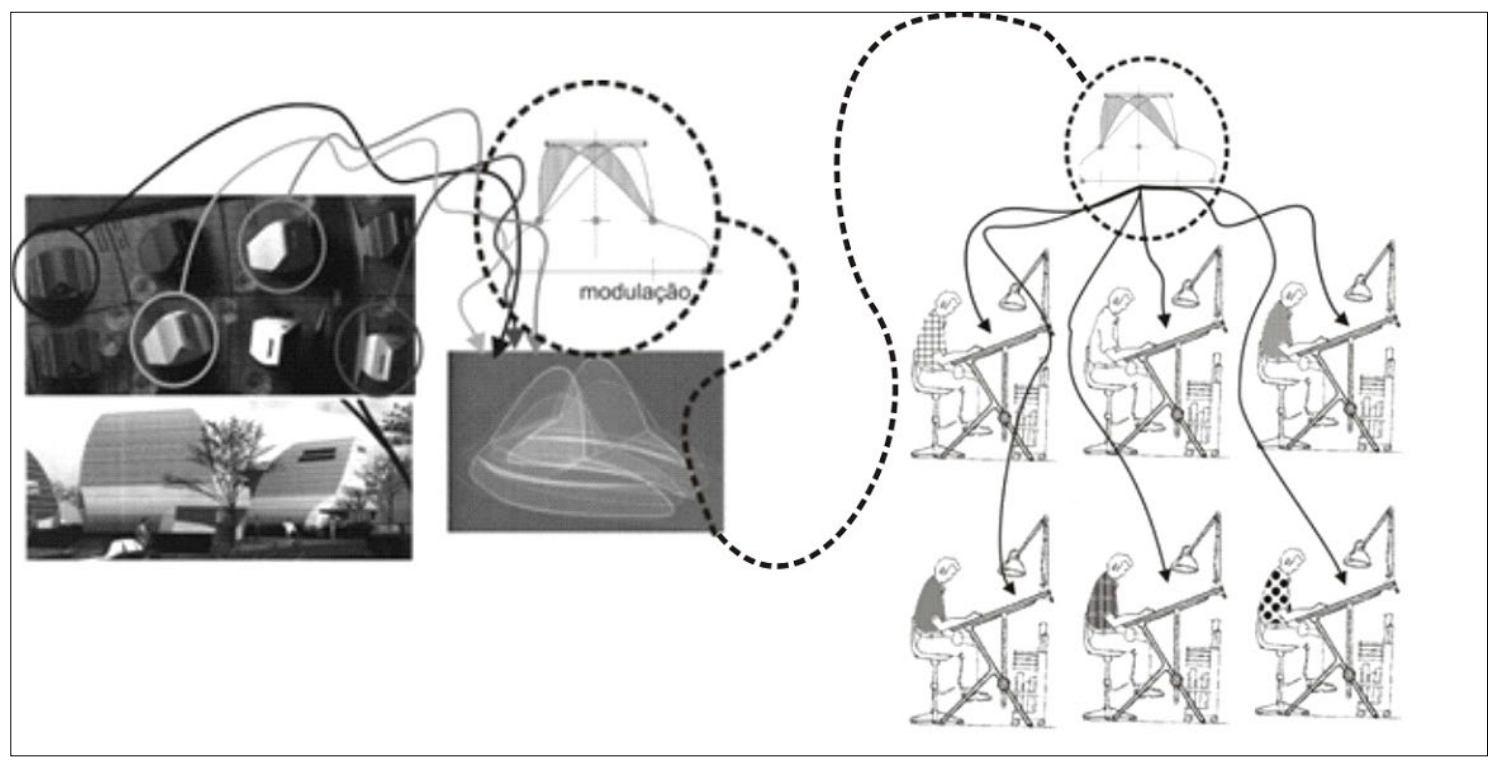

\section{Um novo controle ou a antiga liberdade no mundo das escolhas: 0 modulado}

Tomemos a imagem proposta por Christopher Jones, do processo projetual como a procura de um tesouro, o resultado certo, momento em que o projetista cava freneticamente em prol do lugar exato e pelo resultado certo: o tesouro. Através dessa imagem fica claro o percurso do projeto, do reino infindável de opções para a escolha certa, como explica Gross (1986), um caminho em cujo percurso limitações e objetivos vão sendo adotados a fim de produzir restrições. Parece muito compensador encontrar o tesouro, mas pensar em cavar uma ilha inteira sem nenhum mapa pode ser desestimulante, muitas opções para uma única escolha. Algo parecido com o que Schwartz (2009) chamou de "paradoxo da escolha", exemplificado com a compra de uma calça jeans em uma loja com muitas opções.
Figura 7: Objectile como metaprocesso atravessando diversos trabalhos

Fonte: Elaborada pelos autores 
A questão é que quando se tem muitas alternativas para uma única escolha, a responsabilidade da escolha fica grande demais. Assim, reduzir as opções parece um caminho natural, tomando as rédeas para restabelecer o controle, produzindo restrições e dando direção e sentido ao caminho, como faria um eficiente mapa do tesouro. Projetar, portanto, é buscar conferir sentido e direção a uma ação. Contudo, a introdução da variabilidade como objeto, ou como resultado do processo, abre espaço para que se escolha uma gama de opções, na tentativa de evitar o excesso de responsabilidade. A escolha se torna modulada em um intervalo. A modulação surgiria como um novo tipo de controle e mecanismo de seleção. Em lugar de um projeto preciso, como um blueprint, que emite regras objetivas para a execução, o que aconteceria se o projeto encontrasse sua finalidade nas variáveis, em outras palavras, se o fim do projeto fosse o próprio objeto variável? Trocaríamos controle por liberdade? Precisaríamos de um novo mecanismo de escolha para lidar com a variabilidade.

\section{Controle e liberdade: o objeto variável no processo de projeto paramétrico}

Como já observamos, todo processo de criação lida com uma gama infindável de parâmetros e variáveis, então, projetar passa por controlar e reduzir essas alternativas, a partir da circunscrição de um ou diversos problemas. Contudo, como Gane (2004) alerta, a racionalização de um projeto inicia seu controle com uma simplificação de componentes, sem a qual a mente humana ficaria sobrecarregada e descontrolada. Não por acaso, Gross (1986) define projeto como um modo de explorar restrições. De modo semelhante, ainda que pautado nas variáveis, Gane elenca três componentes do processo projetual diretamente relacionados com as ideias de controle e simplificação: regras, variações e ambiguidades.

Inicialmente o projetista, como em todo trabalho artístico, necessita construir um sistema com o objetivo de nortear a criação e definir normas para as relações de seus componentes. Gane destaca que esse é o papel das "regras", cabendo ao projetista decidir qual regra será dominante e refinará o resultado do projeto, ainda que esse processo muitas vezes seja um pouco confuso e aleatório. Nesse momento, estruturas organizacionais, orientações solares, hierarquias entre alturas de blocos ou qualquer outro aspecto pode ser considerado essencial para definir restrições e associações entre parâmetros, ou seja, produzir controles.

Por outro lado, se a regra restringe os componentes, as variáveis são fundamentais, pois sem flexibilidade o projetista chegará rapidamente a um impasse na tomada de decisão. Assim, todo processo de projeto trabalha com uma gama de variações que podem ser aleatórias (blind variations) ou que tentam aprofundar a investigação do problema. Esse segundo tipo é o mais importante para o processo projetual, porque procura entender e construir relações e hierarquias entre os diversos parâmetros. Gane (2004) destaca duas variações desse tipo, as por intuição (insight) e as por análise gradual (gradual analysis), ou seja, com menos ou mais sistematização e controle na investigação das associações entre parâmetros. Na primeira, a visão é global (algo como top-down), e na segunda, vai crescendo a complexidade (algo como bottom up). Além das regras, as variações também carregam outra espécie de controle, as restrições definidas pela modulação, isto é, a faixa de "tanto até quanto" poderá variar um parâmetro específico. Desse modo, as variações trazem valores e prejulgamentos essenciais para o jogo do projeto, pois ditarão modulações entre níveis máximos e mínimos permitidos, os quais ajudarão a pensar melhor as relações entre diversos subproblemas, estratégia que funciona muito bem quando não sabemos exatamente onde poderemos chegar. Aqui, uma modulação na orientação do edifício poderá viabilizar a definição do brise vertical. 
Esse controle das variações é importante porque ajuda na construção das associações, tornando mais fácil pensar, por exemplo, na janela que trata da iluminação e, ao mesmo tempo, se relaciona com a funcionalidade interna de um ambiente e a composição estética da fachada. A modulação aumenta o controle sobre um jogo de opções flutuantes que possuem algum tipo de relação (modulando, por exemplo, uma faixa de $0.8 \mathrm{~m}$ a $1 \mathrm{~m}$ de paredes laterais internas, para não interferir na funcionalidade). Esses dois conceitos, modulação e controle, tornam-se essenciais para pensarmos o objectile e o projeto paramétrico. Contudo, não devemos nos esquecer do último elemento de Gane: a ambiguidade, elemento que introduz a surpresa através de meios que não estão inteiramente sob controle do projetista, pois além da regra podem existir mais caminhos. Por fim, é verdade que geralmente o emprego das regras busca reprimir a ambiguidade e controlar as variáveis, mas a invenção sempre desafia a estabilidade do projeto e introduz um tipo de liberdade.

\section{O controle modulado}

O conceito de modulado que estamos abordando desde o começo do artigo foi pensado por Deleuze (2007), inspirado na visão do filósofo Gilbert Simondon sobre analogias. Este autor discute três tipos de transporte de informação na geração da forma: molde, módulo e modulado. Para entender o molde pode-se pensar em um balde de areia de praia, que imprime a similaridade de suas ranhuras na areia, funcionando de fora para dentro. Basta alcançar o estado de equilíbrio e voilà: desinformamos. O módulo, ao contrário, trata das relações internas; um molde que imprime de dentro para fora, como ossos de um esqueleto auxiliam na definição da forma de um corpo ou como um grid orienta um edifício. Por fim, o conceito mais relevante aqui, a modulação trataria de uma espécie de molde variável, que não para quando alcança o equilíbrio e continua a se modificar. "Um modulador é um molde temporário contínuo” (SIMONDON apud DELEUZE, 2007, p. 156). Esse modulador controla as variações dos diversos objetos presentes simultaneamente no objectile.

Savat (2005) busca aprofundar essa ideia de modulação a partir do texto de Deleuze "Post-Scriptum sobre as sociedades de controle" (1992), que trata da passagem da sociedade disciplinar para a sociedade de controle. $O$ autor coloca a modulação dentro do contexto social, um tipo especial de controle, em que as pessoas não necessariamente percebem suas ações sendo observadas e registradas através da amplificação dos bancos de dados. Estamos sendo modulados! Essa nova sociedade observa a partir do reconhecimento de padrões, como diz Bogard (apud SAVAT, 2005), um modo de observação que vê antes do fato. Uma sociedade marcada pelo anseio de se programar com antecedência, que planejaria trajetórias e confirmaria qual perfil humano combinaria com elas. Ainda que existam moldes, enquanto houver essa modulação constante, nenhum modelo poderá aderir fortemente a eles.

Deleuze (1992) exemplifica sua teoria com o sistema de ensino continuado, que tende a substituir a escola. No lugar do ensino disciplinar, fragmentado claramente (com início e fim, organizado em séries, etapas do fundamental ao básico, segmentado e com atividades bem definidas), o ensino continuado trata de um aprendizado que nunca acaba, no qual o controle ininterrupto substitui o exame - não para quando alcança o equilíbrio, mas continua a modificar o molde. Podemos estabelecer um paralelo com a ideia de projeto continuado do meta-design, o qual, baseado na suposição de que problemas futuros não podem ser completamente antecipados no momento da concepção, estimula usuários a se tornarem codesigners.

Para pensarmos melhor sobre essa ideia de projeto continuado na sociedade do controle, cabe uma reflexão sobre o que Savat (2005, p. 51) chamou de "mecanismos da modulação", divididos em: reconhecimento de padrões, antecipação de atividades, programação de fluxos e amostra. 
Diferentemente da sociedade disciplinar foucaultiana, a modulação não se concentra nos corpos individuais (como um projeto específico para um edifício), senão no reconhecimento de padrões que os moldam continuamente. Em paralelo, o projeto baseado no objectile não visa controlar a forma como um molde bem definido parece mais com uma peneira "cuja trama varia de um ponto ao outro" (DELEUZE, 1992, p. 221), mas procura padrões gravados no intervalo de variação. O terceiro mecanismo trata da antecipação da atividade, pois o objectile, mesmo antes de saber qual será seu fim preciso, necessita modular as possibilidades. Por outro lado, como explica Savat, esse mecanismo permite acessar os dados em qualquer ponto, sem depender da leitura do código inteiro.

Continuando a comparação, sugerimos que o objectile seja concebido de tal modo que possa entrar em um momento qualquer do processo de projeto, desligado das sequências processuais ali existentes. Em função da exigência de antecipar as atividades, a modulação tende a utilizar instrumentos de modelagem numérica de computador, visando cartografar os fluxos. Por fim, como explica Deleuze (1992), no lugar de massas, esse mecanismo lida com amostras. A preocupação do objectile não seria se definir e se submeter a teste; carrega com ele apenas uma amostragem de possibilidades baseada em padrões. As amostras não necessitam de consciência; são elas as utilizadas para determinar os padrões de consumo (DELEUZE, 1992).

Por essa razão a modulação não trata de uma forma essencial, mas do controle sobre uma família de possibilidades enquadradas por parâmetros. Ela se interessa mais por amostras e previsões do que por produzir uma forma específica e bem definida derivada de um comportamento. Por fim, como a modulação se ocupa de um molde em constante movimento, os "erros" serão cada vez mais controlados e previsíveis, para que, como diz Savat, seu código genético possa vir a ajustá-los. Isso remete ao projeto continuado e constante (meta-design), um controle específico que acontece não através da precisão, mas de modulações e aproximações. Um ambiente definitivamente mais controlado, um novo controle sutil, que se apresenta "na forma de escolha" e liberdade.

\section{Por um novo pensar dentro do projeto: espaço para novas descobertas}

Iniciamos estas reflexões com a lembrança de Cache (2011) sobre a conhecida teoria do paleontólogo André Leroi-Gourhan em $O$ gesto $e$ a palavra. $\mathrm{O}$ autor sugere que, na evolução humana, com a liberação das funções utilitárias das mandíbulas, graças ao andar ereto e bípede, abriuse caminho para a fala. Ou seja, quando o ancestral humano não teve mais que pegar as coisas com a boca, como todos os quadrúpedes, buscou novas funções para ela. Tomando essa lógica, Cache se pergunta: quais tipos de pensar nossa mente poderia exercer no momento que o computador começa a cumprir certas funções do pensamento? Para o francês, o computador seria uma nova força de desnaturação, mas que se resume basicamente a duas ações: calcular e memorizar. Assim, do mesmo modo que a posição vertical libertou o homem para a fala, o computador, calculando e memorizando por nós, abriria campo para novas funções utilitárias da mente.

O pensador francês destaca que este mundo, com a troca de elétrons por fótons, definitivamente soltará os freios da velocidade de cálculo, para então, por exemplo, calcular todos os movimentos possíveis de um jogo de xadrez. Contudo, projetar definitivamente não se trata de um jogo de xadrez. Talvez a comparação mais próxima seja a música (CACHE, 2011; GANE, 2004), porém não se consegue explorar todas as alternativas através de princípios combinatórios. Cache (2011) nos lembra o sonho de Marin Mersenne, em Harmonie universelle (1637), de encontrar a "música perfeita" por meio da análise de combinações revela que a harmonia não é definida 
completamente de modo único. Não há como comparar modulações musicais, ou arquitetônicas da mesma maneira que se poderá fazer com os movimentos de xadrez (CACHE, 2011). O que isso significa? Provavelmente, o controle do cálculo algoritmo das variações e associações também não servirá para alcançar o "projeto perfeito".

Por outro lado, o arquiteto atual pode produzir as próprias ferramentas de criação, talvez como nunca na história, e continuaremos a ampliar a oferta de modelos matemáticos e de cálculo. Para Cache (2011), trata-se da oportunidade para o projetista explorar uma atividade não algorítmica do cérebro. Recorrendo ao teorema da incompletude de Gödel, segundo o qual os sistemas mais complexos nunca poderão ser provados totalmente verdadeiros através de cálculos, podemos pensar que nossas atenções deverão estar no elemento incalculável do pensamento, proposições incapazes de ser demonstradas ou negadas. Cache (2011) observa que entender algo em profundidade implica necessariamente conhecer o que escapa ao seu algoritmo. Nesse caso, a missão do objectile seria modular os cálculos dentro de uma máquina de pensar, um algoritmo, para liberar o pensamento humano, libertar-nos da necessidade de memorizar e do pensar vigiado pela racionalidade algorítmica, como diz Cache (2011), uma liberdade para novas e estranhas faculdades, como a amnésia e a inconsciência algorítmica.

O objectile carregaria uma modulação de relações e variações, uma gama potencial de propostas, ou seja, de cálculos e memórias, sem a pretensão de alcançar o projeto certo ou "perfeito". Esse objeto variável, com capacidade de atravessar diversos processos de projeto, talvez tenha uma missão maior: liberar a mente para novas aventuras.

\section{CONCLUSÃO}

Alguns conceitos podem realmente ser bárbaros, tanto por uma espécie de violência de ruptura, como também pelo desrespeito aos códigos de bom comportamento. Talvez o objectile consista em um destes, fazendo termos como início e fim, controle e liberdade, cálculo e memória se mostrarem desde seus avessos. Esta foi nossa esperada contribuição teórica: entender tais termos. Buscamos demonstrar que a troca do objeto fixo tradicional do processo de projeto por outro em contínua variação, permite emergir "novas pretensões" em relação às ideias de processo, mecanismos de escolhas e formas de pensamento do projeto. A incorporação da variabilidade pelo objeto projetual traz um reposicionamento das noções de início e fim, permitindo pensar um projeto contínuo, que aqui aproximamos do conceito e das pretensões do chamado meta-design: o objectile como meta-objeto.

Essa substituição do objeto fixo pelo variável também produz impacto direto no entendimento dos mecanismos de escolhas dos processos tradicionais. A possibilidade de o projetista ter que lidar com um número maior de escolhas gera novos modos de controle, trazendo a modulação como mecanismo para tratar uma gama de opções. Um tipo de projeto em consonância com as ambições da "sociedade de controle" (DELEUZE, 1992) e do consumo, que sempre se misturam de algum modo. Nesse sentido, o projeto paramétrico representa o desejo de mais controle.

A incorporação da variabilidade por meio do objectile parece ter a missão superior de libertar a mente humana para novas aventuras. Liberdade sempre exige mais responsabilidade. Sem românticas esperanças, novos conceitos podem nos levar a novas possibilidades, sem algozes ou mártires. Como lembra Cache (2011), computador parece ter um valor de desnaturação. Na visão de Gane (2004), um projeto "para pensar primeiro e acima de tudo" revela claramente a ideia de projeto proposta aqui, um meta-processo, que é apenas parte da questão. Afinal, como diz Cache (2011), a codificação é apenas metade da história. 
Descrevemos uma espécie de projeto variável, que parece procurar ser mais compatível com a variação de comportamento da sociedade. Contudo, precisamos falar do projetista, pois o alerta sobre o perigo do controle constante não pode ser esquecido. Como Gane (2004) destaca, o projetista deve estar sempre em guarda para se deixar surpreender, ao mesmo tempo, nas palavras de Cache (2011), lidando com uma espécie de “amnésia”. Vale o pensamento de Kandinsky (apud CACHE, 2011), para quem o perigo da expressão matemática é que ela pode ficar atrás da experiência emocional e limitá-la. No entanto, o objectile também produzirá o superject (o sujeito relacionado ao novo objeto), um sujeito de perspectivas tão variadas quanto a multiplicidade do objectile. Novas perspectivas para novos pensamentos. Nesse sentido, o objectile é apenas parte do processo, não a ambição final. Além do mais, ele nunca teve mesmo a pretensão de ser projeto de nada em específico.

\section{AGRADECIMENTOS}

Agradeço a CAPES pelo fomento ao doutorado, com o qual este artigo mantém relação.

\section{REFERÊNCIAS}

BAUDRILLARD, J. O sistema dos objetos. 4. ed. São Paulo: Perspectiva, 2004.

CACHE, B. Earth moves: the furnishing of territories. Cambridge, MA: The MIT Press, 1995.

Projectiles. London: Architectural Association, 2011.

CACHE, B.; GIRAD, C. Objectile: the pursuit of philosophy by other means? Introduction: a conversation between Bernard Cache and Christian Girard. In: FRICHOT, H.; LOO, S. (Eds.). Deleuze and architecture. Edinburgh: Edinburgh University Press, 2013. p. 96-110.

CARPO, M. Del alfabeto al algoritmo: sobre la autoría digital y el diseño paramétrico. Arquitectura viva, Madrid, n. 140, p. 112-114, $2011 \mathrm{a}$.

The alphabet and the algorithm. Cambridge, MA: The MIT Press, 2011b.

CHOKHACHIAN, A. Parametric design thinking: a paradigm shift for architecture design process. Saarbrücken: Lambert Academic Publishing, 2014.

DELEUZE, G. A dobra: Leibniz e o barroco. Campinas: Papirus, 1991.

Post-Scriptum, sobre as sociedades de controle. In: Conversações: 1972-1990. São Paulo: Editora 34, 1992. p. 219-226.

Pintura: el concepto de diagrama. Buenos Aires: Cactus, 2007.

DELEUZE, G.; PARNET, C. L’abécédaire de Gilles Deleuze. Produção de Pierre-André
Boutang. Entrevista. Tradução para fins acadêmicos de Tomaz Tadeu. Paris: Vidéo Éditions Montparnasse, 1996. Disponível em: <https://goo.gl/LD91bp>. Acesso em: 10 nov. 2017.

DUARTE, R. B. El diagrama arquitectónico despues de Deleuze: estudio de casos holandeses. 2015. 386 f. Tese (Doutorado em Arquitetura) - Universitat Politècnica de Catalunya, Barcelona, 2015

ETHERINGTON, R. 10 Hills Place by Amanda Levete Architects. Dezeen, London, 10 set. 2009. Disponível em: <https://goo.gl/ xqPC4D>. Acesso em: 13 nov. 2017.

FISCHER, G. End user development and meta-design: foundations for cultures of participation. In: DWIVEDI, A.; CLARKE, S. (Eds.). End-user computing, development, and software engineering: new challenges. Hershey: IGI Global, 2012. p. 202-226. Disponível em: <https://goo.gl/Tm7fxm>. Acesso em: 1ำ nov. 2017.

GANE, V. Parametric design: a paradigm shift? 2004. 98 f. Dissertação (Mestrado em Arquitetura) - Massachusetts Institute of Technology, Cambridge, MA, 2004.

GELI, E. R. Media-tic/Enric Ruiz Geli. Archdaily, [S.I.], 9 fev. 2010. Disponível em: <https://goo.gl/z74B3N>. Acesso em: 13 nov. 2017.

GARCÍA ALVARADO, R.; JOFRE MUÑOZ, J. The control of shape: origins of parametric design in architecture in Xenakis, Gehry and Grimshaw. METU Journal of Faculty of Architecture, Ankara, v. 29, n. 1, p. 107-118, 2012. 
GIACCARDI, E. Principles of metadesign processes and levels of co-creation in the new design space. 2003. 436 f. Tese (Doutorado em Filosofia) - Faculty of Science and Technology, University of Plymouth, Plymouth, UK, 2003.

GROSS, M. D. Design as exploring constraints. 1986. $147 \mathrm{f}$. Tese (Doutorado em Filosofia) - Massachusetts Institute of Technology, Cambridge, MA, 1986.

HARTOONIAN, G. Crisis of the object: the architecture of theatricality. London: Routledge, 2006

ITALIAN Architect Reimagines Peroni's Nastro Azzurro Bottle Design with 3D Printing. Microfabricator, Norfolk, 24 jul. 2014. Disponível em: <https://goo.gl/ yHjsCy>. Acesso em: 13 nov. 2017.

KOLAREVIC, B. Architecture in the digital age: design and manufacturing. New York: Taylor \& Francis, 2005. Disponível em: <https://goo.gl/Xw81Gh>. Acesso em: 10 nov. 2017.

KWINTER, S. ¿Quién teme al formalismo? In: ZAERA-POLO, A. (Org.). Filogénesis: las especies de Foreign Office Architects. Barcelona: Actar, 2003. p. 96-99.

LACERDA, T. M. Leibniz: matéria extensa e corpo orgânico. Especiaria: Cadernos de Ciências Humanas, Ilhéus, v. 16, n. 28, p. 153166, 2016.

MONTANER, M. J. Crisis del objeto. In: Sistemas arquitectónicos contemporáneos. Barcelona: Gustavo Gili, 2008. p. 10-25.

MONTEFAMEGLIO, A. Thauma - \#3 objectile: Deleuze, Leibniz and Bernard Cache. Momus: the culutural magazine, [S.I.], 30 maio 2016. Disponível em: <https:// goo.gl/SJPbMn>. Acesso em: jun. 2017.
MORAES, D. Metaprojeto: o design do design. Rio de Janeiro: Blucher, 2010.

NILSSON, F. Architectural objectiles: architecture, form, meaning and experience in the digital era. In: ARCHITECTURE \& PHENOMENOLOGY INTERNATIONAL CONFERENCE, 1., 2007, Haifa. Proceedings CD. Gothenburg: Chalmers Publication Library, 2007. p. 1-13. Disponivel em: <https:// goo.gl/XX3FTX>. Acesso em: 1ำ nov. 2017.

NOX. HtwoOexpo. NoxArch, [201-?]. Projects. Disponível em: <http://www.noxart-architecture.com/>. Acesso em: 13 nov. 2017.

NYAWARA, B. Aqua Tower, a Water Sculpture in the Chicago Sky by Studio Gang Architects. Archute, [S.I.], 28 out. 2015. Disponivel em: <https://goo.gl/ Qp9zV1>. Acesso em: 13 nov. 2017.

ROWE, C.; KOETTER, F. Crisis of the object: predicamento of texture. Perspecta, Cambridge, MA, v. 16, p. 108-141, 1980.

SANDERS, E. B.; STAPPERS P. J. Cocreation and the new landscapes of design. CoDesign, Abingdon, v. 4, n. 1, p. 5-18, 2008. DOI: 10.1080/15710880701875068

SAVAT, D. Deleuze's Objectile: from discipline to modulation. In: SAVAT, D.; POSTER, M. Deleuze and new technology. Edinburgh: Edinburgh University Press, 2005. p. 45-61. Disponível em: <https://goo. gl/ZBJGBe>. Acesso em: 1ำ nov. 2017.

SCHWARTZ, B. Paradox of choice: why more is less. New York: Harper Collins, 2009

TRUMMER, P. Associative design: from type to population. In: MENGES, A.; AHLQUIST, S. (Eds.). Computational design thinking: computation design thinking. London: Wiley AD Reader, 2011. p. 179-194.
Rovenir Bertola Duarte rovenir@uel.br

Malu Magalhães Sanches malu.msanches@hotmail.com

Louisa Savignon Lepri Islepri@gmail.com 
